\title{
Orang-utans in Captivity
}

\section{John Perry}

The author examines the age structure of captive orang-utans in zoos and institutions. He shows that, unless breeding success can be achieved with captive-born animals - which so far no zoo in the world has done - zoo numbers will continue to decline, with little hope of replacement from the wild now that the International Convention on Trade in Endangered Species is in operation. John Perry is Assistant Director for Conservation at the National Zoo in Washington, and a Vice-Chairman of the IUCN's Survival Service Commission.

The number of orang-utans in captivity is approximately $625 .^{1}$ Except for Père David's deer, no other endangered species has so large a captive population. Since the orang-utan's habitat in Borneo and Sumatra dwindles year by year, maintaining this captive remnant is an important goal. According to the latest zoo reports, success is still elusive.

Following publication of the first orang-utan studbook in $1971,{ }^{3}$ Perry and Horsemen found several encouraging signs. ${ }^{4}$ While the first orang-utans brought into zoos did not live long, better diets and disease control had made longevity quite satisfactory. Captive births, once a rarity, had become gratifyingly frequent. Of 460 in captivity in 1969,101 had been captive-born. But no living orang-utan had been born to captive-born parents. There was a single record of an earlier second-generation birth. However, during the 1967-69 period covered by the studbook, only 13 captive-born females were of breeding age.

The latest International Zoo Yearbook (Volume 15) provides a census for early 1974 and birth records for $1973 .{ }^{1}$ Since 1969 , about 140 captive births have occurred. More than one-third of the 625 orang-utans in collections in 1974 were captive-born. No second-generation births had yet occurred, although the number of captive-born females of breeding age is now about $35 .^{2}$

The apparent birth rate, 22 per 1000 in 1964, rose to a peak of 73 per 1000 in 1973. However, the wild-caught orang-utans are ageing, and many have passed the point at which fertility begins to decline. While some captive-born females have successfully mated with wild-caught males, such matings will become less frequent as the males grow older. Unless captive-born pairs begin to reproduce, the birth rate - and total captive population - will decline.

The studbook indicates annual mortality in the captive population is approximately 4 per cent. At this rate, roughly 179 wild-caught orang-utans died between 1964 and 1974. Since the wild-caught population increased by 158 in this period, acquisitions of about 337 are indicated.

At first glance this seems shocking, in view of the international zoo ban against acquiring other than legally-captured and legally-exported orangutans. However, the bulk of the acquisitions occurred before the ban took effect, and the largest subsequent increase has been in Indonesian zoos, which are government repositories for seized and surrendered orang-utans. The indicated acquisitions since 1967 number about 98, of which 40 were in Indonesian zoos. Of the remaining 58, 20 were in Singapore and Kuala 
Lumpur. A number of these were surrendered by private owners. It is believed that others were transfers from Indonesian zoos.

In short, the voluntary zoo ban, together with the controls applied by Indonesia, Malaysia, and several importing nations, appears to have been effective. If our estimates are correct, not more than four or five orang-utans per year have come through the black market.

This does not take into account wild-caught orang-utans which are sold as pets to private individuals, chiefly in Southeast Asia. This trade continues. In the past, many of these were eventually sold to dealers and then to zoos. With this market now largely eliminated, and if 'rehabilitation stations' are available to receive them, some are ultimately surrendered. However, many die of disease and malnutrition. Reports are frequently received of illegal transactions, such as orang-utans captured in the course of logging and exported on timber vessels.

What would have happened if acquisitions of wild-caught orang-utans had stopped in 1967 ? Since that date the captive-bred population has increased by 171 ; the birth rate has exceeded the death rate. By 1974, the captive population would have increased somewhat from the 1967 total of 431. By 1974, however, the wild-caught females would be ten years older, and their number would have diminished by about 34 per cent because of normal deaths. The birth rate would be declining. Soon the total population would also decline, unless captive-bred animals also reproduced.

The Convention on International Trade in Endangered Species of Wild Fauna and Flora, coupled with tighter national controls, will further restrict imports of wild orang-utans. Because of the large number that have been in captivity, the case for further imports is not strong.

The long-term outlook for the captive population is bleak unless births in the second and subsequent captive generations occur with sufficient frequency. With each passing year it becomes more probable that the absence of such births is not mere chance, that something is lacking in zoo management.

At the Yerkes Regional Primate Research Center, Dr David Martin reports that the chimpanzee birth rate has been only half that required to maintain their colony. ${ }^{5}$ Chimpanzees are more prolific than orang-utans, and Yerkes has had fourth-generation chimpanzee births. Dr Martin attributes the short-fall primarily to removal of infants from their mothers. This, he writes, results in chimpanzees 'which are not psychologically normal but sexually mature, and hence they are behaviorally deficient for adequate procreative activity'. Many zoo-born orang-utans are hand-raised because their mothers do not or cannot provide proper care and nursing. The behavioural deficiencies noted by Dr Martin are often seen in male and female orang-utans, not only those zooborn but also those captured as infants.

Yerkes has initiated an artificial breeding programme. Studies of artificial insemination of both chimpanzees and orang-utans have begun. Martin reports progress in the collection and preservation of sperm, but no successful impregnations have as yet been reported.

Zoo men would prefer to solve the problem by more natural means. Success has been achieved with several other mammal species by improvements in diet, redesign of enclosures, and control of the occasions when males and females are kept together. The objective is to simulate more closely the natural circumstances in which these species come together, mate, and rear young. 
While some zoos are experimenting, many are not. Because of their size and strength, manipulating orang-utans is not easy. Shipping them from zoo to zoo is costly. Building or remodelling cages for them is also expensive.

Because so many first-generation births occur, there may be too little feeling of urgency. Indeed, in many cases captive-bred females are put together with wild-caught mates. This may increase the likelihood of successful mating, but it postpones an attack on the main problem. Fortunately there is still time to experiment. The wild-caught population is now declining. The annual number of first-generation births will probably decline from now on. The total captive population will probably soon turn downward also, but the rate of decline will not be precipitate.

Note: The Yerkes Regional Primate Research Center has stopped publication of the Orang-utan Studbook supplement for financial reasons but continues to collect information by yearly questionnaires.

\section{References}

1. DUPLAIX-HALL, N. (ed.) International Zoo Yearbook. Vol. 15, 1975. London.

2. Since the studbook is no longer published, this statement cannot be verified. However, it is highly unlikely that an event of such importance would not be reported.

3. Orang utang Studbook as of December 31st, 1969. Yerkes Regional Primate Research Center, Emory University, Atlanta, Georgia.

4. PERRY, JOHN, and HORSEMEN, DANA LEE. Captive breeding of orang utans. Zoologica, New York Zoological Society, Summer 1972.

5. MARTIN, DAVID. Artificial breeding at Yerkes. Yerkes Newsletter, Vol. 11, No. 1, May 1974. Atlanta, Georgia.

\section{Rhinos in Borneo}

\section{Tom Harrisson writes in the Borneo Research Bulletin:}

The only rhino known in Borneo is the Sumatran or two-horned, smallest of the species and uniquely a rain forest animal. The Borneo form is named by a German zoologist Dicerorhinus sumatrensis harrissoni, after yours sincerely, like whom it is in imminent danger of becoming extinct in the seventies. I saw one fleetingly on the overland crossing between the Bahau headwaters and the Apo Kayan, interior Kalimantan, in October 1945, and am perhaps the last non-native to have done so. Nearly all recent records have been sightings of footprints only, and all of them in the largely uninhabited Segama-Kinabatangan upriver areas of eastern Sabah. The horns and skin have retained their fantastic value with the Chinese as aphrodisiac, so that rhinos have been illegally hunted to death, mostly by far-ranging Iban and Kelabit-Muruts. There are probably not more than twenty (perhaps ten) left on the island; none in Sarawak and Brunei, just possibly one or two in Kalimantan; the rest in Sabah where they are split up in very difficult terrain so that breeding contact is unnaturally difficult.

Other Sumatran rhinos are on Sumatra (perhaps thirty?) and on the mainland in Malaya (1974 enquiries in detail suggest fewer than twelve, mainly in the north), southern Thailand (a few accidentally protected by Communist guerrillas), Burma (some, but the situation is unsure), and possibly in Indo-China (no recent information). There is still no effective conservation for them outside two national parks in Sumatra and Malaya - from which, however, they tend to roam, vulnerably.

The Survival Service Commission plan to step up conservation for the Sumatran rhino and FPS would welcome any recent information from these areas.

As we go to press (January 20) we learn that Tom Harrisson and his wife have been killed in a road accident in Thailand. 